\title{
The Training of Foreign Language Talents with Intercultural Communicative Competence Under the Belt and Road Initiative
}

\begin{abstract}
Dandan Liu
\author{
Liaoning Normal University 116029
}

Abstract

The training of foreign language talents in cross-cultural communication in the context of the "Belt and Road" needs to change teaching concepts, cultivate a sense of two-way cultural exchange, provide relevant crosscultural communication courses, carry out cross-cultural communication practices, integrate language teaching and cultural teaching, and strengthen culture background, cultural background, etc., to build a cross-cultural communicative competence teaching system. This article mainly discusses and analyzes the problems and strategies in the development of cross-cultural communicative competence in the context of the "Belt and Road", and analyzes how to enhance cross-cultural awareness in foreign language teaching, hoping to help crosscultural education.
\end{abstract}

Keywords: the Belt and Road Initiative, cultural communicative competence, foreign language talent training

\section{Introduction}

Strengthening the cultivation of cross-cultural communication skills will help to strengthen the integration, communication and cooperation between different cultures, understand and respect cultural differences, and achieve win-win cooperation between countries. The construction of the "Belt and Road" has put forward new requirements for the cultivation of foreign languages. It is necessary to strengthen the cultivation of cross-cultural communication skills and consciousness, cultivate a large number of practical foreign language talents, apply the learned knowledge to practice, and increase cultural sensitivity to cultivate cultural awareness and improve intercultural communication skills and levels. We are supposed to establish and improve the platform for cross-cultural communicative competence cultivation in practical teaching, thus can improve the cultural exchange mechanism, strengthen experience, practice, participation, cooperation and communication in the teaching process, and improve students' comprehensive use of language.

\section{Problems in the Training of Foreign Language Talents with Intercultural Communicative Competence in the Context of the Belt and RoadInitiative}

\subsection{Insufficient Cross-Cultural Education Discipline System}

In some schools, except for specialized foreign language colleges, cross-cultural teaching is not set up as an independent major. Students have relatively fragmented access to relevant knowledge, a lack of systematic theoretical knowledge, and students lack awareness of intercultural communicative competence. Cross-cultural courses are not offered in international trade majors that have a close relationship with the Belt and Road Initiative, and professional talents are scarce. Besides, most schools 'foreign language education is mainly English education, lack of teaching of other foreign languages, students' weak ability to communicate with non-English languages and cultures, and cannot meet the needs of Russian and Arabic along the Belt and Road. In addition, foreign language teaching mainly focuses on language teaching. The lack of teaching of historical culture, customs, and social background in foreign language teaching may cause communication obstacles or conflicts, affecting the effectiveness of communication. 


\subsection{Imperfect Cross-Cultural Textbooks}

Most cross-cultural foreign language teaching lacks an introduction to ethics, values, history and culture, customs, social background, etc. Foreign language textbooks mostly reflect Western cultural characteristics and cultural connotations. They do not pay enough attention to Chinese excellent traditional culture, which is not conducive to the spread and development of Chinese excellent culture. It also lacks an introduction to the culture of countries along the "Belt and Road". The culture of countries along the route is not fully understood. As a result, cultural input and output are unbalanced, and students are easily affected by "stereotypes" and cultural prejudices, which is not conducive to the development of open culture, affects the realization of cross-cultural education goals, and is not conducive to cultural communication and understanding.

\subsection{Insufficient Professional Staffing}

The "Belt and Road" needs to strengthen economic and trade exchanges and cooperation with countries along the route, therefore, it is necessary to resolve cultural differences and cultural conflicts, and a large number of professionals with professional capabilities and accomplishments. In the actual teaching process, teachers do not have enough cultural understanding and cognition in the small and medium-sized developing countries along the "Belt and Road" to timely infiltrate cultural elements into classroom teaching, affecting the "Belt and Road" intercultural communicative competence teaching quality. Moreover, the teaching process is biased towards the teaching of language. Insufficient attention has been paid to the teaching of cultural background, thinking and cognitive habits, etc., resulting in students not being able to understand the differences between cultures in different countries and adopt more suitable methods for communication.

\subsection{Lack of Effective Practical Teaching}

In our country's linguistics teaching process, there is generally too much emphasis on the teaching of theory, and the investment in practical teaching is obviously insufficient, which affects the overall effect of teaching and is not conducive to the use of the knowledge learned by students to effectively solve practical problems. In foreign language teaching, there may be a very good understanding and familiarity with grammatical structures and language vocabulary, but the level of listening and speaking is not enough, which is the so-called "dumb foreign language". The lack of communication and communication links in the classroom teaching process and lack of foreign languagerelated activities in daily life cause students' ability to speak and speak in front of the public are weak. Besides, the students also has weak ability to express their opinions and ideas in foreign languages. In the teaching process, teachers need to continuously expand the channels and channels for students to contact and understand foreign languages, and expand their horizons.

\section{STRATEGIESINTHETRAININGOFFOREIGN LANGUAGETALENISWITHINIERCULTURAL COMMUNICATIVECOMPETENCEUNDERTHE BACKGROUNDOFTHFBELTANDROADINITIATIVE}

\subsection{Update Educational Philosophy}

The training of foreign language talents with intercultural communicative competence in the context of the "Belt and Road" needs to update educational concepts and change teaching models. On the one hand, the training of foreign language talents with cross-cultural communicative competence is taken as a development strategy, to strengthen communication with different cultures, adhere to the people-oriented thinking, and meet the development needs from a strategic perspective. Pay attention to the cultivation of students 'cultural identity and cultural resonance, focus on the cultivation of students' thinking patterns and values, and establish a positive and healthy attitude towards cross-cultural communication. Combining language teaching and cross-cultural comprehensive quality training to enhance students' awareness of intercultural communicative competence. On the other hand, transforming the training mode of talents are important to develope a cross-cultural communicative talent as a systematic project, they are integrated into humanistic quality education. Increase the level of cultural education, increase the teaching of multicultural characteristics courses, accept and understand cultural differences, and build a dynamic and adaptable cross-cultural communication model. In addition, strengthen language communication, strengthen cultural understanding and trust, and strengthen multilingual and multicultural training methods. Open nonEnglish language majors or courses to broaden cultural horizons.

\subsection{Rich Educational Materials}

The training of foreign language talents with intercultural communicative competence in the context of the "Belt and Road" requires the enrichment of educational materials and the strengthening of cultural heritage teaching. The first is to improve the construction of cross-cultural specialty teaching materials and optimize the curriculum. Comprehensively analyze the professional nature and characteristics of students in different disciplines and the needs of the "Belt and Road" construction and development, moderately adjust the theme and value orientation of crosscultural education, develop multicultural courses, and provide richer teaching materials. The second is to make reasonable use of network resources for teaching, broaden channels for knowledge acquisition, enrich teaching forms, 
and make cross-cultural teaching more comprehensive, lively, and intuitive. The third is to enhance students' awareness and attitude of intercultural communication ability, appreciate and accept different cultures, and exert cultural value. Carry out teaching for countries along the "Belt and Road", improve the knowledge structure and system of students, and provide cultural elective courses such as Arabic and Russian, so that students can systematically and comprehensively understand Chinese culture and the culture of countries along the route, and then objectively and comprehensively review And solve problems faced in actual communication. The fourth is to strengthen the teaching of cultural heritage, continuously understand the excellent Chinese culture and the cultural characteristics and connotations of countries along the "Belt and Road" countries, and conduct extensive exchanges and communication. On this basis, establish a bridge for communication between the two sides and improve crossborder communication Cultural communication ability and level. Foreign language learning requires not only learning phonetics, grammar rules, and vocabulary, but also strengthening cultural awareness teaching, understanding local customs and cultural backgrounds, and strengthening the penetration of cultural awareness such as foreign language background knowledge.

\subsection{Improve the Construction of College Teachers}

The training of foreign language talents with intercultural communicative competence in the context of the "Belt and Road" needs to improve the construction of teachers in universities. First, strengthen school-enterprise cooperation, international exchanges and cooperation, etc., and improve cross-cultural practical ability teaching. Teachers can be regularly selected to participate in practical inspections, research activities, visits to schools, and foreign language teachers can be invited or hired for teaching, so as to deepen teachers' understanding of the language and culture, thinking patterns, values, and religious beliefs of countries along the Belt and Road And cognition to strengthen communication and communication between different cultures. The second is to cooperate in running schools, introduce high-quality teachers, exchange international students, etc., establish and improve cross-cultural experience and exchange platforms, improve multicultural compatibility, and promote more flexible and creative cultural exchanges and contacts. Third, school-enterprise cooperation provides students with learning opportunities, cultivates students' comprehensive language skills, and uses their knowledge for cross-cultural communication and communication.

\subsection{Enhance Cross-cultural Practice Teaching}

The training of foreign language talents with intercultural communicative competence under the background of the
"Belt and Road" needs to strengthen cross-cultural practical teaching. Make full use of various extracurricular resources to encourage students to take an active part in curriculum development. Through English magazines, movies, videos, novels, radio, etc. to expand channels and ways for students to contact and understand foreign languages, and expand students' horizons. You can also use the Internet and social software to understand and understand the culture and characteristics of relevant countries in communication and communication, and enhance cultural awareness. Carry out some rich cultural activities, create a good atmosphere for foreign language learning, and stimulate student interest. Intensify and expand teaching in teaching, strengthen the teaching of language background, cultural background, and practice, and increase the knowledge of foreign language learning. Learn about national emotions, attitudes, values, multi-level, multi-angle, and multi-channel cultivation, and strengthen the introduction of foreign language culture. In addition, it is necessary to set up relevant practice and exercise opportunities, speech competitions, debates, group activities, etc. to improve students 'ability to speak and speak in front of the public, and through various practical teaching activities, students' ability to express their opinions and ideas.

\section{CONCLUSION}

In summary, under the "Belt and Road" context, it is necessary to strengthen the cultivation of intercultural communication skills and consciousness, and to cultivate a large number of practical foreign language talents who have the ability to use multiple languages, multicultural knowledge, cultural tolerance and an attitude of acceptance. The learned knowledge is put into practice, strengthening exchanges, communication and cooperation between countries, increasing cultural sensitivity and fostering cultural awareness. In actual teaching, it is necessary to change teaching ideas, enrich teaching forms and content, strengthen the construction of talent teams, establish a platform for the cultivation of cross-cultural communication skills, improve the cultural exchange mechanism, and strengthen experience, practice, participation and cooperation in the teaching process and exchanges to deepen the understanding of culture and improve students' comprehensive ability to use language.

\section{ACKNOWLEDGMENT}

This research is supported by the Social Science Planning Youth Fund of Liaoning Province, China,titled "Pragmatic Acquisition of Language-learning Behaviors from the Perspective of Social Cognition".L19CYY006

\section{REFERENCES}

[1] Liu Yanfen, Zhang Chunfang, Yang Fan. Investigation 
and Research on the Status Quo of Cross-cultural Foreign Language Talent Training in Colleges and Universities in Hebei Province [J]. Journal of Xingtai University, 2019 (04).

[2] Ma Zhenqiu, Lu Xianwei. Research on the Status Quo and Countermeasures of Foreign Language Talent Training in Tangshan City [J]. Cultural Education Materials, 2016 (26).

[3] Mu Linjie. Recognition of Intercultural Communicative Competence Training under the Belt and Road Initiative [J]. Journal of Shaanxi Pre-College Normal University, 2017 (03).

[4] Zhang Weidong, Yang Li. Construction of Intercultural Communicative Competence System_—Based on Foreign Language Education Perspective and Empirical Research Methods [J]. Foreign Languages, 2012 (02). 